Trivent Publishing

(C) The Authors, 2018

Available online at http:/ / trivent-publishing.eu/

TRIVENT

Series: Applied Ethics: From Bioethics to Environmental Ethics

\title{
Neuroethics and Moral Enhancement: The Path to a Moral World?
}

\author{
Maria Sinaci \\ "Vasile Goldis" West University of Arad, Romania
}

\begin{abstract}
A central theme in the bioethical debates of the $21^{\text {st }}$ century is human enhancement, approached from different perspectives, such as cognitive or aesthetic enhancement - however, the most provoking approach is that of moral enhancement. A society with a majority of moral people is a historial dream of humankind, and some researchers argue that we may be nearing it. This chapter discusses several conceptual and ethical issues resulted from moral enhancement. It aims to show that today's direct interventions of moral enhancement, which are supposed to make man more moral, fail in their aim to make the world a better place.
\end{abstract}

Keywords: ethics; buman enhancement; bioethics; neuroethics; moral enhancement

This is an Open Access article distributed in accordance with the Creative Commons Attribution Non Commercial (CC-BY-NC-ND 4.0) license, which permits others to copy or share the article, provided original work is properly cited and that this is not done for commercial purposes. Users may not remix, transform, or build upon the material and may not distribute the modified material (bttp:/ / creativecommons.org/ licenses/by-nc/4.0/) 


\title{
Neuroethics and Moral Enhancement: The Path to a Moral World?
}

\author{
Maria Sinaci
}

\section{Introduction}

As imperfect beings, people have always had the desire to improve their condition: be healthier, be more visually appealing, live longer, be more intelligent and even be kinder, that is, more moral. Because of the scientific progress of the past few decates, these aspirations can become, at least partially, a reality. The purpose of new biotechnologies is not solely curative and aimed at the treatment of major medical conditions or disabilities; new biotechnologies now also aim human enhancement. Science now offers possibilities which were unthinkable a few decades ago with respect to the enhancement of certain characteristics of the human nature - possibilities which allow people to be "better than well" [1].

The concept of human enhancement is increasingly present in the academic environment, although it is used in a variety of methods - which leads to the conclusion that it is not clearly understood. Some specialists use it when referring to interventions which increase or intensify certain capacities. Others are more restrictive and use it exclusively for the description of those interventions which go beyond the medical field - thus, they create a border line between therapy and the extension of human capacities beyond therapy. In Beyond Therapy [2], the President of the Council on Bioethics defined enhancement in contrast to therapy, arguing that enhancement is the usage of biotechnological power to modify, through direct intervention, not the processes of disease and illness, but the "normal" functioning of the human body and mind, in order to increase or improve their native capacities. Chatterjee [3] makes the same distinction, arguing that biomedical enhancement refers to interventions used for the enhancement of certain capacities beyond normal, rather than re-establishing certain functions or 
capacities lost because of illness. In a functional-argumentative approach, "interventions are considered enhancements ... insofar as they [augment] some capacity or function (such as cognition, vision, hearing, alertness) by increasing the ability of the function to do what it normally does" [4, p. 2].

Biomedical human enhancement aims different zones, such as cognition, memory, certain physical abilities or personality and behavioural traits, thus generating intense debates on the ethics of enhancement. However, the most recent challenge of ethicists is represented by moral enhancement, proposed by some as a solution to the serious moral problems of humanity. J. Săvulescu și I. Persson [5] [6] argue for the necessity to enhance human moral behavior, because, they say, people are not psychologically and morally prepared to face today's global problems. Therefore, they affirm the necessity of moral enhancement methods such as using pharmaceutical products, neurostimulation, genetic editing, or any other type of biological method which can be used for this purpose. Generally, there is a hope within those who support moral enhancement that new biotechnologies could contribute to the construction of a better world through the enhancement of moral reasoning, the increase of pro-social behavior, and the strengthening of moral virtues. It would seem that the benefits of a society composed of as many moral people as possible are evident. But would this be possible? Is this the path towards a moral world? Is morality an objective for all people?

Before answering these questions, certain conceptual observations are necessary, which is why the following section will discuss the terminology on morality, moral enhancement, and neuroethics.

\section{A terminological frame}

In a wide sense, morality may be defined as "beliefs about what is right behaviour and what is wrong behaviour" [7]. However, this definition is somewhat relative and ambiguous. Establishing what is right and wrong in the behaviour and actions of a person is a central theme within debates on the standards of morality. Bernard Gert [8] is sceptical on having a sole definition of morality which could be applicable to all moral discussions - this is because morality seems to be used in two wide senses: descriptive and normative. Morality is linked to behaviour and authors such as T. M. Scanlon [9] and S. Darwal [10] highlighted the social nature of morality. The intentions and behaviour of each moral agent affects the well-being of others. Therefore, a larger number of moral invididuals in a community would increase the wellbeing of that entire community. The growth of the level of morality is not a new preoccupation - it has been present, in a specific form, in the religious sphere since Antiquity, and in monotheistic religions. The novelty in moral enhancement stands in the way it can be realized, through the most recent 
scientific descoveries such as neurobiology, neuropsychology, neurosociology, neurosciences, pharmacology, and of course medical biotechnologies. The ethical and philosophical implications which appeared within this context led to the birth of a new field, namely neuroethics.

The term "neuroethics" was used initially to indicate certain ethical aspects present in clinical neurology and brain research. Later on, the field and the procedures of neuroethics extended, enlarging its sphere of competence. The introduction and the establishment of the term is attributed to William Safire who defined it as "the examination of what is right and wrong, good and bad about the treatment of, perfection of, or unwelcome invasion of and worrisome manipulation of the human brain... [neuroethics] deals with our consciousness - our sense of self - and as such is central to our being" [11, p. 5]. In her article Neuroethics for the new millennium [12], Adina Roskies, neurologist and philosopher, proposes an approach of neuroethics in two divisions: the ethics of neuroscience and the neuroscience of ethics. The first division, the ethics of neuroscience is neuroethics as applied ethics. It investigates the ethical implications and questions arised in the research and usage of neuroscientific technology; furthermore, it also investigates whether its applications are in conformity with ethical values and principles. The neuroscience of ethics investigates empirically the biological basis of ethical thought and behaviour and the way in which it could influence ethical thought, as well as the way in which the brain generates thought and moral action. One of the topics of neuroethics, for instance, refers to the way in which intuitions are generated. Which parts of the brain are involved and how does the brain work in order to make a moral agent believe that a particular action is forbidden, allowed, or mandatory? Furthermore, it interprets philosophical notions such as free will, personal identity, intention, altruism, and value judgement.

The study of the brain and the new neurotechnologies have stimulated researchers towards the study of morality, especially concerning the human behaviour and emotional dispositions. But how could one define moral enhancement? What would being "more moral" mean? Several definitions exist on moral enhancement, but there is no consensus on them. Some definitions concentrate on moral behaviour or the effects of behaviour, while others concentrate on the process of moral decision-making, on human virtues, or on cognitive and affective capacities. According to T. Douglas [13], there are interventions which, in an anticipatory way, will give an individual more moral reasons or behaviours than (s)he would otherwise have had. Karim Jebari [14] understands moral enhancement as an improvement of empathy. I. Persson and J. Savulescu [15] consider that moral enhancement encompasses several factors, such as emotions, empathy, and reasoning. A more precise definition from the perspective of how one can intervene for the 
purpose of moral enhancement is given by B. Earp și J. Savulescu [16]. The authors discuss moral neuroenhancement which acts directly on the brain and propose the following definition: "Any change in a moral agent-effected or facilitated in some significant way by the application of a neurotechnologythat results, or is reasonably expected to result, in the agent being a morally better (i.e., more moral) agent" [16, p. 4]. H. Wiseman proposes a more concise definition for biomedical moral enhancement as following: "Some technological or pharmacological means of affecting the biological aspects of moral functioning, to boost what is desirable, or remove what is problematic" $[17$, p. 6]. However, beyond all the nuances of these definitions, the collective element in them is the scope of moral enhancement: the correct moral behaviour.

\section{Is there a biological basis of morality?}

The studies on the biological basis of thought and ethical behaviour have inevitably led to the question of whether there exists a biological basis of morality. In fact, the question regarding the origin of morality has existed for centuries in the thoughts of philosophers, theologians, and not only. The development of neurosciences, biology, psychology, and genetics, has allowed the empirical approach of certain questions, thus leading to the development of a naturalist frame capable of explaining the biological origin of moral behaviour. The research of the past few years, which explores the connections between the brain and morality, prove that the idea of a biological basis of morality has to be taken into consideration.

The most prominent supporter of the idea that morality is rooted in the biology of the brain is Patricia Churchland [18, 19]. Churchland [18] argues that morality is formed in a neurobiological frame which was submitted to evolutionary and cultural pressures, and modelled through interconnected cerebral processes, which eventually led to moral behaviour. The dimensions of this neurobiological frame are the following:

a. Care - rooted in the biological attachment towards family and friends and the care for their well-being

b. The ability to recognize psychological states - rooted in the benefits coming from the anticipation of the behaviour of others

c. Resolving issues in a social context

d. Learning social practices (positive and negative)

It is unclear however if the dimensions of P. Churchland are sufficient to answer all aspects of ethical thought. The essential element of moral behaviour is considered to be social interaction. Beyond this however, it seems that our moral behaviour is influenced by biological factors. Therefore, the studies 
which explore the connection between the brain and morality have led to interesting results: the levels of oxytocin and vasopressin influence high-level social phenomena such as trust, generosity, or punishment. Although Churchland demonstrates that a certain hormone, oxytocin, stimulates prosocial moral behaviour, it does not mean that we can conceive morality as being innate and we cannot, at least for the moment, connect it to a specific gene. However, the argument of the author that morality has biological roots proves that our moral behaviour is not solely motivated by reason. A research conducted by J. Green et al. [20], done by using functional MRI, has demonstrated the existence of cerebral areas which become active when the subject is involved in the evaluation of moral situations or even when his/her answers are lies.

Other researchers have also focused on this subject and argue for a biological basis of morality. Thus, the studies of an American group of researchers, demonstrated that moral judgement is influenced by genes which produce or regulate the neurotransmitters of each neural system involved [21]. The results suggest that the variation in the oxytocin receptor gene (OXTR) is associated with differences in moral judgement. According to the authors, "these data provide the strongest evidence to date linking variation in a specific gene to variation in moral judgment.." $[21$, p. 6]. The research done with the help of functional MRI have shown that "true" or "false" arguments activate different areas of the prefrontal cortex [22].

Research has shown that there is a link between moral thought and the biological aspect, but a gene responsible for morality is yet to be identified. Despite this, studies demonstrate that, on a cerebral level, neural systems allow for a moral judgement, based on neurotransmitters produced by certain genes. Interventions on neurotransmitters have been proven to have significant influence on moral judgement. All this leads to the fact that a biological basis of morality needs to be taken into consideration. If a moral biological basis exists, then moral enhancement is possible by stimulating/inhibiting the biological elements involved. However, it remains to be discussed what exactly influences moral enhancement, moral knowledge, motivation, or moral behaviour. Nevertheless, we consider that the specifics and particularities or morality are not given by biology. What biology offers, especially through the action and adjustement of neurotransmitters, are certain tendencies towards action, such as a sense of correctness, empathy, care for others, respecting rules - in other words, the general ability to develop a moral system. The specific rules we apply in our society are not given by biological data, but are given by moral agents. 


\section{Types of moral enhancement}

The promoters of moral enhancement (most of whom consider traditional moral education to be inefficient) argue that biotechnological means should be used in order to increase the level of morality and strengthen humans from a moral point of view. Their argument is mostly related to the benefits this would bring to communities. If the genetic and biological influences on decision-making and morality are well understood, their enhancement with with certain products and technologies could be considered. Accoding to recent studies (V. Dubljevic și E. Racine [23]), direct interventions on moral enhancement are divided in two types: neuropharmacological interventions and neurostimulation interventions. Studies have shown that moral judgement is produced through the coordinated interaction of several neural systems, each of which is based on a characteristic set of neurotransmitters whose adjustement can influence moral judgement. Interventions on neurotransmitters can have significant influence on moral judgement. For instance, oxytocin (also known as the "moral molecule") raises pro-social behaviour such as empathy, altruism, cooperation, and trust within the social group [24, p. 150, 190]. Research also suggests that variation in the OXTR (variation in the oxytocin receptor gene) most likely influences moral judgment by modulating the influence of oxytocin in the neuron, pathways that have previously been identified as preferentially supportive of ethical moral judgment [25].

Serotonin, another neurotransmitter, modifies moral judgement and behaviour by increasing the subjects' aversion towards harming others. Therefore, it could promote pro-social behaviour. Once morality is demonstrated to have, at least partially, a biological support, it could become influenced by pharmacological interventions. Taking as example the aggressive behaviour, studies in genetic behaviour and neurosciences have shown that a biological basis for violence does exist [26]. There are drugs which increase the control of impulse and can thus contribute to the moral behaviour of people. Ritalin is the drug which reduces violent impulses and contributes to moral enhancement by increasing the capacity to concentrate and think more deliberately on how to resolve issues and conduct ethical analyses. Modafinil also increases pro-social behaviour, such as empathy, cooperation, and trust $[27$, p. 2, 3]. Antidepressants (SSRIs - selective serotonin reuptake inhibitors) generally reduce aggression and seem to make people more cooperative, sensitive and less critical towards their peers. Amphetamines can be used to increase motivation of action. Neurosciences now seem to be able to explain, largely, the functions and biology of the brain, so that the neurotransmitters which are not doing their "job" correctly can be pointed out. Should one be depressed, they can receive antidepressants; should one be antisocial, they can 
rely on products which adjust the balance of neurotransmitters and reduce violent impulses. Could the "morality pill" strengthen self-control, empathy, goodwill, while also decreasing violent tendencies?

Besides neuropharmacological interventions, morality can also be enhanced by direct interventions on the brain with the help of noninvasive neurostimulation technologies. Transcranial magnetic stimulation (TMS), which is the less invasive, transmits magnetic impulses through the brain. A study conducted in 2006 concluded that this treatment can influence the way people respond to moral dilemmas. Transcranial direct current stimulation (tDCS) uses direct electrical currents to stimulate specific parts of the brain. It can increase cooperation and neuroplasticity, favouring the learning of prosocial behaviour [28]. Previous studies have shown that this treatment can influence the way in which people respond to incorrect offers and duties which imply moral judgement. Experimental neurostimulation has demonstrated that these treatments make people more involved in utilitarist judgements, from a moral point of view. Deep brain stimulation (DBS) is a neurosurgical procedure (which involves implanting electrodes in areas of the brain) which some believe can increase motivation [29], [30]. Cabrera et al. [31] highlights that using DBS, TMS and tDCS may produce headaches and can affect the personal identity in ways which cannot be anticipated (such as changing the thinking pattern).

J. Savulescu proposes a revolutionary technology for the purpose of moral enhancement, that is, genetic screening. Savulescu argues that when using in vitro fertilisation, parents have the moral obligation (not only liberty) to choose the embrio which can lead the life with the most well-being. The obligation is moral, not legal [32]. Genetic screening also implies the moral obligation of choosing the most ethical children: "Indeed, when it comes to screening out personality flaws, such as potential alcoholism, psychopathy and disposition violence, you could argue that people have a moral obligation to select ethically better children..." [33].

For the moment, human enhancement is the "hands" of pharmacology, but it will soon be linked to genetic engineering, nanotechnology, neurosciences, virtual reality, and other emerging fields, making its study increasingly challenging.

\section{Moral Enhancement or Moral Treatment?}

Recent debates focus on the difference between moral treatment and moral enhancement. Some philosophers argue that there is a difference between increasing the moral behaviour from an underdeveloped to a normallydeveloped level and from a normally-developed to a highly-developed level. Others define moral enhancement as any type of moral bettering, without 
using an average level to which moral abilities would be linked. N. Agar [34], for instance, considers that moral enhancement only refers to interventions which increase moral abilities to a level above the one already observed. N. Agar [35] also observed that therapeutical interventions can eventually modify deficiencies, while they can also "produce unbalanced excesses when used to enhance beyond human norms" (p. 369). Therefore, the two terms (moral enhancement and moral treatment) are different and should be used accordingly.

DeGrazia [36] defines enhancement as "any deliberate intervention that aims to improve an existing capacity, select for a desired capacity, or create a new capacity in a human being" (p. 1). This definition covers both biomedical and non-biomedical enhancement (such as education). Horskötter et al [37] argue that the interventions meant to restore normal moral abilities in subjects whose moral functioning was pathologically affected should be included in the sphere of moral treatment, not enhancement (p. 27).

The distinction between moral enhacement and treatment raises several issues. One of them is the normative level, as it implies the introduction of a level of normality between the insufficient moral functioning and the aboveaverage moral functioning. Moral treatment would lie below this level of normality, wheareas moral enhancement would be above the level. There is no consent so far on where this average (normal) level of moral behaviour is situated. The question is: HOW does one determine the normal functioning limits of moral abilities? Which types of behaviours and disfunctionalities classify one person below the level of normality?

A distinction of the interventions used in both moral treatment and enhancement may also be necessary. However, there are cases when the same type of intervention (such as pharmaceutical) may be therapeutic at first, but once the person reaches the average level of morality, the intervention becomes enhancement. Therefore, when do we define intervention as a means of treatment or as a means of enhancement? Furthermore, there may be cases when an intervention with pharmaceutics has moral enhancement as side effect. Does that person want to be enhanced morally or is his/her choice violated? Should we consider that everything below the level of normality belongs to the treatment sphere, immorality may be justified as a medical issue. Who should determine whether one is normally moral? Or, when should normal functioning be diminished so as to enter the pathological sphere? Could emrbio genetic selection of the most ethical children be justified, as proposed by J. Savulescu? This work is not written from this perspective, but we consider that in time, as biotechnologies develop and the conceptual apparatus is better defined, the distinction between moral treatment and moral enhancement will bring new theoretical and practical clarifications. 


\section{Is moral enhancement possible, permitted, or mandatory?}

As seen above, moral bioenhancement is possible through several means, at least on an individual level. For now, enhancement technologies are still in the early stages of development or they are still purely theoretical. Nevertheless, some pharmaceutics with medical prescription (drugs, pills), some supplements or stimulation devices (such as transcranial magnetic stimulation) are already used and available on the medical or black markets. Furthermore, some pharmaceutics with medical prescription, used on the wide scale, influence the moral behaviour of consumers. Neil Levy et al. [38] point to three drugs which modify moral decision and behaviour: propranolol, antidepressants (SSRI), and products which influence oxytocin. Similarly, a study conducted in 2013 by Terbeck et al. [38] concluded that subjects who use propranolol (for high blood pressure), men and women, are "more likely to judge sacrificial actions as morally unacceptable." Propranolol influenced morality especially in terms of personal dilemmas and seemed to increase aversion towards hurting others. Furthermore, "subjects who took propranolol were more likely to make deontological judgments, and to reject contrary utilitarian solutions to moral dilemmas, but only when these utilitarian solutions involved 'up close and personal' harm to an innocent victim" [38].

Antidepressants reduce aggression and may influence people into being friendlier or more sensitive towards others' pain. Pharmaceutics, like Ritalin and Adderal, improve the control over impulses in children with attention deficits, reducing violence. However, improving a characteristic involved in moral action may lead to diminishing another or even to immoral choices. For instance, increased self-control could lead to the lack of risk taking. Oxytocin was proved to enhance altruistic behaviour and empathy, but only within one's social group [39, p. 190]. Oxytocin could diminish cooperation with members outside the group, such as rasial minorities, promoting selective ethnocentrism, favouritism, and even aggression towards other groups [40]. Ruud ter Meulen highlighted that while some medicine can increase moral behaviour, others (or sometimes the very same) could have the opposite effect [41].

The preoccupation with this field, as well as the studies which showed that chemical substances in the brain can affect certain judgement and moral decisions, have stimulated imagination, thus discussions on the "morality pill" increased after the year 2011. Although a pill which could improve moral behaviour seems closer to fiction, Guy Kahane argues that although the field is only in its incipient phase, "it is very far from being science fiction" [42]. Kahane says that scientists will develop this type of medicine and will create new ways of ingesting them, giving the example of oxytocin taken as nasal spray [42]. Although we are yet to buy the "morality pill," the possibility of moral enhancement with the help of pharmaceutics generated debates whether 
such interventions should be permitted or if the obligation of moral bioenhancement should actually exist. The supporters of moral bioenhancement often give arguments on the benefits of strengthening prosocial behaviour, such as the inclination towards empathy, collaboration, aggression reduction, etc. The diminishment of acts of violence and of antisocial acts in general would imply a reduced number of incarcerated people. However, we highlighted before that strengthening some characteristics may lead to the diminishment of others and create imbalances which can generate immoral acts [43, p. 150]. Persson and Savulescu [44] [45] argue that moral enhancement should be mandatory. Savulescu argues for genetic screening, which may be a new form of eugenics [46]. He also states that "if safe moral enhancements are ever developed, there are strong reasons to believe that their use should be obligatory, like education or fluoride in the water, since those who should take them are least likely to be inclined to use them. That is, safe, effective moral enhancement would be compulsory."

Therefore, we consider that moral bioenhancement, on an individual level, will be possible, but within a timeframe which cannot be predicted. As seen, bioenhancement already exists, in certain incipient forms. Biotechnologies in the field of neurosciences and genetics is progressing so rapidly that what seemed impossible just a few decades ago, is now possible. The major interest for the study of the brain is reflected in the large budgets allocated to research projects so that while the $20^{\text {th }}$ century was the century of the DNA, the $21^{\text {st }}$ century may be regarded as the century of the brain. We mention within this context the Human Brain Project, with a budget of $€ 1$ billion over ten years (2013-2023), with support from the European Commission and from other partners including universities, industries and Member States' own programmes, and with the implication of over 400 researchers from 24 countries [47].

\section{From individual moral enhancement to the moral enhancement of humanity?}

Most definitions state that direct moral enhancement refers to interventions done on people individually. However, some scholars also include the interventions done on groups or even on humanity, in general. I. Persson and J. Savulescu discuss the improvement of the moral character of humanity. The enhanced characteristics which they discuss the most are altruism, trust in the members of the group, empathy, self-control (in the sense of reducing violence and anti-social behaviour), the will to cooperate, etc. As already obvious, the aim of these characteristics' enhancement is pro-social behaviour. However, definitions may differ with regard to the aim of moral enhancement. T. Douglas [48, p. 3] defines moral enhancement as the interventions which give 
a larger number of motivations and moral behaviours to an individual than (s)he would normally have. I. Persson and J. Savulescu argue for the enhancement of humanity through the moral obligation of selecting more moral children: "The genetically programmed child is in production ... People have a moral obligation to select ethically better children" [44] [45]. This implies to genetically examine embrios with the scope of determining which one has superior ethical qualities. What happens with the less ethical embrios? The moral enhancement of humanity would be based on a procedure involving genetic screening and selective embryo abortion. Such a program is contested and considered immoral by both some bioethicians and religious groups. The two authors nevertheless consider that methods should be put forward to enhance morality through pharmaceuticals, genetic editing, or any other method. The supporters of bioenhancement thus hope that new biotechnologies could contribute to a better world by improving moral reasoning, pro-social behaviour, and the strengthening of moral virtues. But would this be possible in reality? Would this be the path to a more ethical and moral world? And, furthermore, is morality an objective for all people?

The products and procedures mentioned above are debatable not only from a moral point of view, but also from the point of view of their production methods and their (side) effects. Although they seem to offer benefits to the society, they can have negative, unthought-of results. Because the ethical problems resulted from moral bioenhancement represent a large theme and are not the main purpose of this chapter, the following part will present a summary of some of these problematic aspects: favouring abuse; individual freedom; personal identity and undermining authonomy; lack of moral diversity and debates; the overestimation of moral enhancement; paying less attention to side effects, risks, and safety; a new eugenics by "projecting" moral children and embryonic selection; the risk of having, in time, the obligation of moral enhancement; the lack of freedom to act in an immoral way.

\section{Why is bioenhancement not the path towards a more ethical world?}

This section discusses the possibility of global moral bioenhancement starting from interventions such as the usage of pharmaceutics, neurostimulation, or genetic editing. Our premise is that moral bioenhancement, applied on the level of humanity, is not feasible. The interventions subtly influence pro-social behavior (empathy, lack of violence, voluntary action, etc.). However, morality is much more than this and cannot be reduced to its pro-social dimension, regardless of how important it is. Therefore, a broad definition of morality is needed, which would also encompass a set of universal and desirable virtues 
and traits capable of being enhanced. However, who should determine, globally, what is moral and immoral? This set of virtues and principles should be mandatory and accepted by everybody. We should also not neglect people's religious beliefs, which are different and solid. Therefore, before moral bioenhancement is implemented globally, a series of debates on global ethics should take place. Of course, bioethics had its path opened through Principlism, being a set of universally-applicable principles coming from collective morality. But moral bioenhancement raises specific ethical issues. If the project fails globally, two separate groups of people will exist: enhanced and non-enhanced, that is, moral people and the rest of them. It is known that there is no moral gene. However, researchers argue that biology (for instance, through the levels of oxytocin) can influence morality and external interventions would thus adjust/modify moral levels. Should those with low speficic biological values (such as oxytocin) be considered immoral? Which authority would determine the average level of these biological values beyond which a person would be considered moral? And how could such a procedure be controlled globally so as humanity would be enhanced? For the moment, this is an impossible endeavour. External interventions on neurotransmitters can lead to change in behaviour, but they do not change who the person is, they do not make that person better in his/her essence. Giving up on farmaceuticals, for instance, would most probably lead to the person going back to his/her original state. Who would have the global or even local control of such a process? Of course the benefits of a moral society are numerous, if its members voluntarily choose enhancement. They should be allowed to choose, not be manipulated or have paternal interventions inflicted on them. There will always be people who will not wish to be moral.

The solution of J. Savulescu and I. Persson is that of genetic screening, argued to be a moral obligation of parents who choose in vitro feritilisation. Would non-ethical embrios then be destroyed? Such a procedure is rejected by people with profound religious beliefs. Some issues still remain: that of taking responsibility, standardizing, and applying on global level. Even so, there will be children conceived naturally, born from unethical parents, who cannot, for the moment, be genetically screened.

Furthermore, there is the issue connected to the efficiency of these interventions, brought into attention by Veljko Dubljevic' and Eric Racine [49]. They studied previous research done on using enhancement technologies, evaluating both their effects and the way in which they can be practically applied. Their conclusion is the following: "the predicted effects of state of the art of neurointervention simply do not materialize ... In sum, an analysis of current interventions leads to the conclusion that they are blunt 'instruments:' any enhancement effect is unspecific to the moral domain" [49, p. 348]. 


\section{Conclusion}

The field of neuroethics is not only an emerging one, but is also a challenging one as it has a tremendous dynamics, in the context of the development of other connecting fields which it intersects. Moral enhancement has a special place within debates, with some being interested in the enhancement of the individual, and others seeing it as way of making the world a better place. Athough some researchers argue for clear effects on human behaviour generated by neuropharmaceuticals, others argue in the complete different direction. We think that the possibilities of moral enhancement are somewhat overestimated which leads to exaggerations (at least for the moment), such as the enhancement of humanity. The risks of the interventions are numerous and the ethical problems remain unsolved. We do not exclude the possibility of moral enhancement (such as in the case of violence and not only), but it should be done through objective analyses, while trying to avoid excess on each side. Of course biotechnologies and pharmaceuticals can be an important resource for solving several moral problems, but only on an individual level, not on a community or global level. Once technology reaches a certain level, the advance in research cannot be stopped, but as much as moral enhancement progresses, we consider that it cannot replace traditional moral education. Education creates a change within the being, in its essence, and is accessible to everyone. Nevertheless, the "morality pill" may be closer to its achievement than we imagine, and if so, no boundaries can stop it.

\section{References}

[1] C.Elliott, Better Than Well: American Medicine Meets the American Dream. New York and London: W. W. Norton and Company, 2003.

[2] The President's Council on Bioethics, Beyond Therapy: Biotechnology and the Pursuit of Happiness. Washington, D.C., Oct. 2003, available at: https://bioethicsarchive.georgetown.edu/pcbe/reports/beyondtherapy/in dex.html. Accessed: April 15, 2017.

[3] A. Chatterjee, "Cosmetic neurology: the controversy over enhancing movement, mentation, and mood", Neurology, 63, 968-974, $2004 . \quad$ doi: 10.1212/01. WNL.0000138438.88589.7C

[4] B. D. Earp, A. Sandberg, G. Kahane, and J. Savulescu, "When is diminishment a form of enhancement? Rethinking the enhancement debate in biomedical ethics", Frontiers in Systems Neuroscience, 8 (12), pp. 1-8, 2014.

[5] I. Persson and J. Savulescu, Unit for the Future. The Need for Moral Enhancement. Oxford: Oxford University Press 2012. 


\section{Maria Sinaci \\ Neuroethics and Moral Enhancement}

[6] I. Persson and J. Savulescu. "Getting moral enhancement right: the desirability of moral bioenhancement". Bioethics 27, pp. 124-131, 2013. doi: 10.1111/j.1467-8519.2011.01907

[7] Merriam-Webster [Internet]. Springfield, MA: Merriam-Webster, Incorporated; 2015 [2015; August 1st, 2016], available at: http:// www.merriam-webster.com/dictionary/morality. Accesed: April 10, 2017.

[8] B.Gert, The Definition of Morality.2016, available at: https://plato.stanford.edu/entries/morality-definition/ . Accessed: April 10, 2017.

[9] T.M. Scanlon, "Contractualism and Utilitarianism", Utilitarianism and Beyond, A. Sen and B. Williams eds., Cambridge: Cambridge University Press, pp. 103-28, 1982.

[10] S. Darwall, The Second-person Standpoint: Morality, Respect, and Accountability. Cambridge: Harvard University Press, 2005.

[11] W. Safire,"Introduction", Neuroethics: Mapping the Field, 1st edition, S. J. Marcus (ed.), New York: Dana Press, pp.3-10,2004.

[12] A. Roskies. "Neuroethics for the new millennium," Neuron 35, pp. 21-23, 2002.

[13] D.Thomas, "Moral Enhancement," Enhancing Human Capacities, edited by Julian Savulescu, Ruud ter Meulen, and Guy Kahane, eds., Wiley-Blackwell, Apr. 2011.

[14] K. Jebari, "What to Enhance: Behaviour, Emotion or Disposition?", Neuroetbics 7(3), pp. 253-261, December 2014.

[15] I. Persson and J. Savulescu, "The perils of cognitive enhancement and the urgent imperative to enhance the moral character of humanity", Journal of Applied Philosophy, 25(3), pp.162-177, 2008.

[16] B. D. Earp and J.Savulescu, Moral neuroenhancement, July 2017, https://www.researchgate.net/publication/305776669 Accessed: Sept 10, 2017.

[17] H. Wiseman, The Myth of the Moral Brain: The Limits of Moral Enhancement. Cambridge, MA and London: The MIT Press, 2016.

[18] P. S. Churchland, Braintrust. What Neursscience Tells Us about Morality. Princeton, Princeton University Press, 2011.

[19] P. S. Churchland, Touching a Nerve. The Self as Brain. New York - London: W. W. Norton and Company, 2013.

[20] J. D. Greene, R. B. Sommerville, L. E. Nystrom, J. M. Darley and J. D. Cohen, "An fMRI investigation of emotional engagement in moral judgment", Science, 293 (5537), pp. 2105-2108, 2001.

[21] R. M. Bernhard, J. Chaponis, R. Siburian, P. Gallagher, K. Ransohoff, D. Wikler, R.H. Perlis and J. D. Greene, "Variation in the oxytocin receptor 
gene (OXTR) is associated with differences in moral judgment", Social Cognitive and Affective Neuroscience, pp. 1-10, 2016.

[22] J. F. Marques, N. Canessa, S. Cappa, "Neural differences in the processing of true and false sentences: insights into the nature of 'truth' in language comprehension", Cortex 45, pp. 759-768 [PubMed], 2009.

[23] V. Dubljević, E. Racine , "Moral Enhancement Meets Normative and Empirical Reality: Assessing the Practical Feasibility of Moral Enhancement Neurotechnologies", Bioethics, vol. 31, no. 5, pp. 338348, 2017. doi:10.1111/bioe. 12355

[24] D. G. Jones, "Moral Enhancement as a Technological Imperative", Perspectives on Science and Christian Faith 65, pp. 187-95, 2013.

[25] M. B. Regan, J. Chaponis, R. Siburian, P. Gallagher, K. Ransohoff, D. Wikler, R. H. Perlis and J. D. Greene, Variation in the oxytocin receptor gene (OXTR) is associated with differences in moral judgment", Social Cognitive and Affective Neuroscience, pp.1-10, 2016, doi: $10.1093 /$ scan/nsw103

[26] T. Douglas, "Moral Enhancement", Journal of Applied Philosophy, 25, pp. 228-45, 2008.

[27] T.J. Trothen, "Moral Bioenhancement through An Intersectional TheoEthical Lens: Refocusing on Divine Image-Bearing and Interdependence", Religions, 8 (5), 84, pp. 1-14, 2017. doi:10.3390/rel8050084.

[28] A. Piore, "A Shocking Way to Fix the Brain". MIT Technology Review, 2015, available at:

https://www. technologyreview.com/s/542176/a-shocking-way-to-fix-thebrain/ Accessed: April 20, 2017.

[29] V. Dubljevic, M. Shipman, "Study: 'Moral Enhancement' Technologies Are Neither Feasible Nor Wise".

https://news.ncsu.edu/2017/05/moral-enhancement-tech-2017/ Accessed: September 15, 2017.

[30] [23] V. Dubljević, E. Racine , "Moral Enhancement Meets Normative and Empirical Reality: Assessing the Practical Feasibility of Moral Enhancement Neurotechnologies", Bioethics, vol. 31, no. 5, pp. 338-348, 2017. doi:10.1111/bioe. 12355

[31] L. Y. Cabrera, E. L. Evans and R. H. Hamilton, "Ethics of the ElectrifiedMind: Defining Issues and

Perspectives on the Principled Use of Brain Stimulation in Medical Research and Clinical Care", Brain Topography 27, pp. 33-45, 2014.

[32] J. Savulescu, "Procreative beneficence: why we should select the best embryos," Bioethics, 15.5/6 pp. 413-426, 2001.

[33] The Telegraph, Genetically engineering 'ethical' babies is a moral obligation, Richard Alleyne, 16 Aug 2012, http://www.telegraph.co.uk/news/science/science- 
news/9480372/Genetically-engineering-ethical-babies-is-a-moralobligation-says-Oxford-professor.html. Accessed: April 20, 2017.

[34] N. Agar, "Enhancing genetic virtue?", Politics and the Life Sciences 29(1), pp. 73-75, 2010. doi:10.2990/29_1_73.

[35] N. Agar, " A question about defining moral bioenhancement". Journal of Medical Ethics, 40(6), pp. 369-370, 2014.

[36] D. DeGrazia, "Moral enhancement, freedom, and what we (should) value in moral behaviour". Journal of Medical Ethics, pp.1-9, 2013. doi:10.1136/medethics-2012-101157.

[37] D. Horstkötter, R. Berghmans, G. de Wert, "Moral enhancement for antisocial behavior? An uneasy relationship", AJOB Neurosci, 3(4), pp. 2628, 2012.

[38] N. Levy, T. Douglas, G. Kahane, S. Terbeck, P. J. Cowen, M. Hewstone and J.Savulescu, ,"Are You Morally Modified? The Moral Effects of Widely Used Pharmaceuticals", Philos Psychiatr Psychol, 21(2), pp.111-125, 2014. doi:10.1353/ppp.2014.0023.

[38] S. Terbeck, G.Kahane, S. McTavish, J. Savulescu, N. Levy, M.

Hewstone, Philip J. Cowen, ,"Beta adrenergic blockade reduces utilitarian judgement", Biological Psychology, 92 (2), pp. 323-328, 2013.

doi: $10.1016 /$ j.biopsycho.2012.09.005

[39] Jones, D. Gareth, "Moral Enhancement as a Technological Imperative", Perspectives on Science and Christian Faith, 65, pp. 187-95, 2013.

[40] C.K.W. De Dreu, L.L Greer, G.A. Van Kleef, S. Shalvi and M.J.J. Handgraaf, "Oxytocin promotes human ethnocentrism", Proc Natl Acad Sci U S A.; 108, pp. 1262-1266, 2011.

[41] [42] A. Hill, Manipulating morals: scientists target drugs that improve behaviour, available at:

https://www.theguardian.com/science/2011/apr/04/morality-drugsimprove-ethical-behaviour. Accessed: April 20, 2017.

[43] [24] D. G. Jones, "Moral Enhancement as a Technological Imperative", Perspectives on Science and Christian Faith 65, pp. 187-195, 2013.

[44] [6] I. Persson and J. Savulescu. "Getting moral enhancement right: the desirability of moral bioenhancement". Bioethics 27, pp. 124-131, 2013. doi: 10.1111/j.1467-8519.2011.01907

[45] I. Persson, and J. Savulescu, "The art of misunderstanding moral bioenhancement". Camb. Q. Healthc. Ethics 24, pp. 48-57, 2014. doi: $10.1017 / \mathrm{S} 0963180114000292$

[46] R. Alleyne, Genetically engineering 'ethical' babies is a moral obligation, Aug 2012 https://www.telegraph.co.uk/news/science/sciencenews/9480372/Genetically-engineering-ethical-babies-is-a-moralobligation-says-Oxford-professor.html. Accessed: September 15, 2017. 
[47] https://ec.europa.eu/digital-single-market/en/news/europeancommission-signs-agreement-take-human-brain-project-hbp-next-phase. Accessed: September 20, 2017.

[48] T. Douglas, "Moral Enhancement Via Direct Emotion Modulation: A Reply to John

Harris", Bioethics, 27(3), pp. 160-168, 2011.

[49] [30] [23] V. Dubljević, E. Racine, "Moral Enhancement Meets Normative and Empirical Reality: Assessing the Practical Feasibility of Moral Enhancement Neurotechnologies", Bioethics, vol. 31, no. 5, pp. 338-348, 2017. doi:10.1111/bioe.12355 